\title{
Comunicação Intercultural: Prática social, significado político e abordagem científica
}

\author{
Mohammed ElHajji ${ }^{1}$ \\ UFRJ \\ mohahajji@yahoo.com.br
}

\begin{abstract}
Resumo: Este artigo se propõe de examinar e co-relacionar as diversas facetas constitutivas do fenômeno da interculturalidade - a partir de sua manifestação e cristalização no campo comunicacional. Busca-se apreender a questão da Comunicação Intercultural (CIC) na sua tripla natureza social, política e científica. Enquanto prática social, interface e vetor dialógico entre os diversos segmentos identitários, culturais, étnicos, nacionais $e$ confessionais componentes da paisagem social e política contemporânea. E como superfície discursiva, horizonte de análise e estudo para a compreensão dos mecanismos de luta e de negociação da cidadania e do espaço político por esses mesmos segmentos.
\end{abstract}

Palavras-Chave: Comunicação Intercultural; Comunicação Comunitária; Identidade Cultural; Pluri-Pertencimento.

Resumen: Este artículo propone examinar y co-relacionar las diversas facetas constitutivas del fenómeno de la Interculturalidad - a partir de su manifestación y a partir de su cristalización en el campo comunicacional. Nuestro objetivo es aprehender(temer) la cuestión de la Comunicación Intercultural (CIC) en su naturaleza social, política y científica. Como práctica social, interfaz y vector dialogado entre los segmentos identitaires, culturales, étnicos, nacionales y confesionales que componen el paisaje contemporáneo social y político. Y como superficie discursiva, horizonte de análisis para la comprensión de los mecanismos de lucha y de negociación de la ciudadanía y del espacio político por estos mismos segmentos.

${ }^{1}$ Doutor e Comunicação e Cultura. Professor do Programa de Pós-Graduação da ECO/UFRJ. 
Palabras-clave: Comunicación Intercultural; comunicación Colectiva; identidad Cultural; multipertenencia.

\begin{abstract}
This article intends of to examine and to co-relate the several constituent facets of the intercultural phenomen - starting from its manifestation and crystallization in the communication field. It is looked for to apprehend the Intercultural Communication in its social, political and scientific nature. While social practice, interface and dialogical vector between the several cultural, ethnic, national and confessional components segments of the social and political contemporary landscape. And as discursive surface, analysis horizon and study for the understanding of the fight and negotiation mechanisms for the citizenship and of the political space.
\end{abstract}

Keywords: Intercultural Communication; Community Communication; Cultural Identity; multi-adherence.

Resumé: Cet article se propose d'examiner et de mettre en relation les diverses facettes constitutives du phénomène de l'Interculturalité - à partir de sa manifestation et de sa cristallisation dans le champ communicacionnel. Notre objectif est d'appréhender la question de la Communication Interculturelle (CIC) dans sa triple nature sociale, politique et scientifique. En tant que pratique sociale, interface et vecteur dialogique entre les segments identitaires, culturels, ethniques, nationaux et confessionnels qui composent le paysage social et politique contemporain. Et comme superficie discursive, horizon d'analyse pour la compréhension des mécanismes de lutte et de négociation de la citoyenneté et de l'espace politique par ces mêmes segments.

Mots-clés: Communication Interculturelle; Communication Communautaire; Identité Culturelle; Multi-appartenance. 
O presente artigo objetiva iniciar, dentro do campo da Comunicação, um debate teórico analítico em torno da problemática da Interculturalidade e da Comunicação Intercultural (CIC) enquanto marcos centrais da paisagem social e política da Atualidade e pontos nevrálgicos reveladores das grandes e difíceis transformações pelas quais passa a sociedade contemporânea.

\section{A Problemática}

Se não há como ignorar a realidade irreversivelmente multicultural de nosso mundo, as dúvidas persistem quanto ao significado deste fato e as suas implicações sociais, políticas, civilizacionais e filosóficas. Tampouco se vislumbra um consenso convincente quanto aos direitos, prerrogativas, status e responsabilidades que se pode outorgar à Comunicação Intercultural - meios e conteúdo confundidos; no afã de privilegiar o diálogo construtivo entre as diferentes franjas culturais e étnicas da sociedade e tornar públicos seus discursos auto-reflexivos.

De fato, uma das vantagens da CIC (tanto pela participação e visibilidade na mídia geral como - principalmente através das práticas comunicativas comunitárias) é de dotar a sociedade de interfaces comunicacionais que possibilitem uma maior transparência aos projetos sociais, políticos e culturais dos grupos constitutivos da sociedade multicultural (grupos étnicos, culturais, confessionais ou/e nacionais), evitando assim amalgamas, desconfiança desnecessária, suspeitas infundadas e preconceitos disfarçados.

Pois, ao mesmo tempo que este tipo de mídia sustenta a comunicação intracomunitária e serve de instância de enunciação de sua identidade coletiva (incluindo a sua visão do mundo, suas crenças, sua filosofia, seus ideais políticos, seus modelos sociais, etc..), ele não deixa de ser uma janela aberta sobre a comunidade, da qual toda a sociedade pode exercer seu legítimo (republicano) “droit de regard”. Por outro lado, a própria instituição de canais formais de comunicação comunitária incentiva os grupos componentes da paisagem multicultural atual a elaborar discursos coerentes e em sintonia com os ideais supremos da sociedade geral na qual elas se inserem.

Ou seja, além de constituir um terreno sólido para o estabelecimento de um modus vivendi baseado na confiança mútua e na transparência, a mídia comunitária 
ou a presença midiática comunitária exigem dos grupos e comunidades culturais um certo grau de coerência entre seus discursos internos e externos. Já que nos planos social, intergeracional e interinstitucional (pelo fato da inevitabilidade de contato entre os membros da comunidade e seus pares da sociedade geral), não parece viável a longo prazo (ou até a médio prazo) manter discursos contraditórios, duplos ou demasiadamente ambíguos nos planos intracomunitários e intersociais.

Portanto, antecipando a tese final deste artigo, podemos afirmar que, ao contrário de que se pode pensar, a CIC (na sua forma midiática comunitária étnica, notadamente) pode prevenir ou remediar ao fechamento comunitário ou comunitarismo fechado que ameaça vários grupos pelo mundo. Mesmo no caso das comunidades mais conservadoras e/ou belicosas, pela regra da coerência discursiva, a CIC pode se revelar um antídoto contra as tentações da exclusão e da animosidade e do ódio de natureza racial, religiosa ou cultural. Ou, pelo menos, pode deixar tais tendências flagrantes e evidentes para toda a sociedade, possibilitando assim a tomada das medidas jurídicas cabíveis e as posturas políticas necessárias para a manutenção da paz e garantia da convivência harmoniosa dentro da sociedade.

A questão da CIC se torna mais urgente ainda quando se observa que no atual momento de profunda perplexidade e de deflagração generalizada do sentido e do sentimento, a atitude psicológica e a tendência política predominante é de barricadas defensivas, desconfiança acirrada do Outro e recolhimento patológico sobre si. Não é por acaso que o discurso hegemônico vigente na maior parte do mundo busca suas raízes nas narrativas escatológicas mais aterrorizantes e volta a se nutrir das fobias e paranóias mais arcaicas.

A alteridade e a diferença ou são escamoteadas e negadas - de algum modo conjuradas ou são cada vez mais naturalizadas, essencializadas e investidas de uma aura negativa, demoníaca, má, nociva, perniciosa e aviltante. Paradoxalmente, a nossa época marcada pela aceleração dos processos de comunicação, de trocas tanto simbólicas como físicas e materiais é também a era do Reino absoluto da Alterofobia.

Não parece mais ter espaço discursivo, midiático e político para celebrar a diferença complementar e enriquecedora que fertiliza o Humano e frutifica suas múltiplas experiências subjetivas e civilizacionais - sem negar a sua indispensável 
unidade no devir planetário e sua unicidade na origem compartilhada da espécie. Medo, desconfiança e desejo da aniquilação do outro, da alteridade, do diferente e da diferença são, doravante, a palavra de ordem generalizada que move as relações entre grupos, nações, estados, culturas e civilizações.

Porém, ao mesmo tempo que se pode observar claramente uma volta das ideologias mais reacionárias e mais friorentas nos segmentos majoritários da sociedade; ao mesmo tempo que o medo e o horror ao Outro se erguem em planos geopolíticos e em programas de governo, é mais espantosos ainda ver os próprios movimentos comunitários e comunitaristas geralmente minoritários, recentemente ainda saudados como barreiras humanas contra o totalitarismo do Sistema Capitalista e sua correlata Indústria Cultural uniformizante, se encontrarem hoje fortemente atraídos pelo ralo fascitizante da exclusividade paroxística e da diferença irremediável que, em vez de negociar as suas relações com o Outro, simplesmente o nega e lhe nega todo direito à simples existência.

Aos sentimentos solidários forjados na consciência histórica de compartilhamento das mesmas condições sociais e do destino político comum (próprios ao comunitarismo aberto, progressivo, progressista, ideal e idealista que vai ao encontro do Outro), são hoje substituídos espectros do pertencimento religioso mítico-mitológico e/ou biológico, racial, étnico e (desculpem o trocadilho fácil) sanguinário de tanto insistir no seu aspecto sanguíneo.

Comunitarismo mesquinho, fechado, reacionário e regressivo que só se efetiva, atualiza e realiza na negação da alteridade, no ódio da diferença e no desprezo do humano - ou na mutilação deste humano para limitá-lo às peculiaridades intrínsecas a seu grupo restrito e expulsar da própria esfera da humanidade todos aqueles que não cabem na sua fantasmagoria elitista.

Não é preciso lembrar que a matriz filosófica e o espelho teórico tanto das conhecidas ideologias de Estado como das narrativas deste segundo comunitarismo plantaram seu arcabouço conceitual no terreno de uma certa literatura culturalista que deturpou a tradição antropológica pluralista, fascinada pela diferença e pelo mistério da diversidade humana, e a aprisionou nos etnocentrismos reducionistas e nos universalismos estreitos, suprematistas e exclusivistas. 
"Cultura", na verdade, se tornou um substituto de "Raça" que justifica o ódio e a abominação do outro, e busca manter as mesmas estratégias discursivas de inferiorização, dominação e opressão de todos aqueles que, de alguma maneira, incomodam aos projetos hegemônicos mal acabados tanto das comunidades fechadas como das nações autocentradas.

Um dos principais sintomas deste movimento regressivo que assola a época moderna e não augura nenhum futuro feliz para as utopias humanistas, é que exclusivismos nacionais e comunitarismo fechados andam de mãos dadas. Não são incompatíveis ou opostos, mas sim duas facetas de uma mesma realidade apocalíptica, dominada pela intolerância conservadora e a auto-suficiência retrograda.

\section{Raízes Históricas e Contexto Atual}

A realidade sociopolítica contemporânea, não é nenhuma novidade, é profunda e irremediavelmente marcada pela flagrante inadequação entre os planos nacional-estatal e cultural-identitário. Os fluxos e refluxos migratórios devidos aos processos de colonização e descolonização, assim como à explosão de setores econômicos e industriais usuários de mão de obra numerosa e/ou de competências específicas, deixaram rastros definitivos na topografia social da maior parte do planeta. A utópica homogeneidade cultural, confessional, étnica ou lingüística, que sustentava os ideais nacionais e nacionalistas herdados da alta modernidade, não passa mais de um referencial abstrato relegado aos manuais da História positivista.

Inúmeros estudos demonstraram, ao longo do século, que o fato intercultural é central para qualquer esforço de compreensão das transformações sociais em curso. Apesar de todas as estratégias de sistematização da experiência humana e de seu enquadramento no projeto jacobino, de neutralização dos anseios de singularidade e de diferença, as manifestações identitárias acabaram se impondo como pólo aglutinador das subjetividades e base de organização comunitária de segmentos importantes da sociedade.

Desde o início do século passado, percebeu-se que a multiculturalidade tornava-se cada vez mais a regra da realidade social das grandes metrópoles de que um fenômeno excêntrico passageiro. A organização comunitária a caráter cultural 
(incluindo suas vertentes lingüísticas, religiosas, étnicas, etc...) não se limitava mais às formações mafiosas ou aos hermetismos culinários, mas sim impregnava até as atividades tidas como racionais e impessoais ao exemplo dos bancos e das organizações empresariais.

De fato, uma das características da sociedade moderna é a sua complexa composição por categorias sociais distinguíveis "com continuidade histórica" e a coexistência, "harmoniosa ou não", de uma pluralidade de tradições cujas motivações podem ser ocupacionais, étnicas, religiosas ou outras. Por outro lado, apesar de sua ação desterritorializante e uniformizante, o modelo organizacional moderna estimula, dialeticamente, a formulação de quadros comunitários não-instrumentais propícios à afirmação da singularidade e à resistência às tentativas de sua homogeneização.

É verdade que, muitas vezes, o contexto moderno favorece, em primeiro lugar, as articulações a caráter vocacional, reduzindo os quadros identitários à sua função opcional, cuja finalidade não é a expressão efetiva de subjetividades singulares, mas apenas o aproveitamento da possibilidade de construção de uma narrativa que sustente interesses e desenhos específicos e imediatos do indivíduo. Pois, por causa da redução de suas opções sociais de realização enquanto sujeito pleno, o indivíduo moderno busca modos de inserção em grupos de interesses semelhantes aos seus para poder alcançar seus objetivos de afirmação tanto material como subjetiva. As instâncias de enunciação da cultura do grupo, enquanto marcas diferenciadas, passam, assim, a se expressar sob novas formas e via novos canais, de tal maneira que possam conciliar a preocupação identitária com outras articulações a caráter vocacional ou profissional.

Porém, graças a sua capacidade de se organizarem paralelamente e até em função das determinações do Mercado, essas instâncias têm a vantagem de constituir uma manifestação viva do desejo visceral de ser e de se afirmar enquanto marca diferenciada num mundo que funciona no princípio da uniformização e categorização das populações, artificialmente sintetizadas e congeladas nas premissas estatísticas e projeções de necessidades e hábitos de consumo. 
A identidade étnico-cultural (que pode incluir elementos nacionais, lingüísticos e/ou religiosos), em especial, se revelou um poderoso catalisador ideológico, capaz de secretar complexos mecanismos de estruturação da vida social sob todas as suas formas. Funcionando, notadamente, como molde (parcial ou predominante) dos quadros simbólicos que estabelecem os critérios de reconhecimento e as regras de conduta dentro do próprio grupo e nas relações com o resto da sociedade. O desejo de diferenciação das comunidades humanas é, com certeza, inerente a seus próprios processos de auto-organização e de afirmação enquanto entidades coesas e coerentes.

Assim, ao se estruturarem em torno de seus sistemas comuns de classificação e de representação do real, através de seus respectivos sistemas de comunicação e suas instâncias de enunciação de sua identidade coletiva, os grupos sociais visam a instituição e a perpetuação de uma marca distinta capaz de consolidar seus interesses materiais, ideológicos e afetivos. Portanto, no afã de assegurar a sua continuidade e se impor enquanto diferença diante outras formas sociais, a comunidade cultural é obrigada a definir seu projeto existencial e delimitar seus campos e níveis de operacionalidade; notadamente através de seus sistemas de comunicação tanto internos como externos. Inversamente, os marcos identitários da comunidade são naturalmente pregnantes de um conteúdo reflexivo e uma dimensão comunicativa que determinam seu posicionamento político e social no quadro geral da sociedade.

Todavia, essa multiplicidade dos quadros identitários (ou pluripertencimento) que, com certeza, é uma preciosa fonte de riqueza simbólica, pode também ser (e muitas vezes é) portadora de conflitos latentes ou manifestos e incompatibilidades potenciais ou expressas em termos de lealdade e de reconhecimento, tanto ao nível abstrato dos valores culturais e civilizacionais como no plano organizacional concreto de atitudes e comportamentos sociais e políticos.

Neste sentido, a CIC tem um duplo valor socio-científico. Além de servir de interface social intercomunitária, ela constitui um quadro epistêmico capaz de efetivar as condições teóricas e analíticas necessárias para a apreensão do significado dos fluxos migratórios a partir de seus rastros comunicativos. Enquanto horizonte epistemológico, a CIC pode oferecer um plano reflexivo altamente operacional, 
seguro e confiável para manobras teóricas inéditas e audaciosas, capazes de trilhar profundamente a complexidade sociopolítica da época contemporânea e retraçar de modo bastante fiel o emaranhado geocultural da era global.

\section{Processo de Globalização e Princípio Geocultural}

Com o processo de globalização, a questão do pluri-pertencimento, da múltipla lealdade e da incompatibilidade dos valores sociais e culturais de grupos constitutivos do mesmo espaço estatal nacional está chegando ao paroxismo de sua exacerbação. Se o distanciamento geográfico e a relativa lentidão das comunicações da época pré-global ainda permitiam uma re-elaboração mais aprofundada da identidade minoritária de origem no ambiente local de destino, hoje, à medida que se configure uma nova esfera étnico-cultural transnacional, se torna mais problemática a desvinculação do universo simbólico inicial ou o afastamento das comunidades "irmãs" espalhadas pelo mundo.

Para uma apreensão significativa desta mudança, primeiro há de salientar a natureza info-temporal e tecno-organizacional do processo de globalização - já que a particularidade da época contemporânea reside na rearticulação das relações sociais e de produção em torno das Novas Tecnologias de Comunicação. A especificidade dessas tecnologias, por sua vez, consiste no deslocamento das instâncias de mediação política, econômica e social da dimensão espacial para a temporal, e a instituição do princípio de instantaneidade e de imediatez como base de regulação de nossa experiência significativa.

É conhecida a proposta da equação que possibilite o cálculo do grau de "encolhimento" do planeta em função da velocidade tecnicamente possível para cobri-lo. O que significa que as distâncias "vividas" entre diferentes pontos do espaço físico são inversamente proporcionais ao tempo necessário para atravessá-las, tornando, assim, virtualmente possível a utopia do mundo como "um lugar só”, na medida que o próprio das NTCs é, justamente, a instantaneidade.

O conceito de globalização, portanto, não deve ser entendido em relação ao globo terrestre, mas sim no sentido da globalidade de uma ação ou de um processo, ou seja, a sua realização ou a sua vivência simultânea em múltiplos pontos do espaço. É essa equação que possibilita o surgimento efetivo e concreto das culturas e 
identidades transnacionais, fundadas numa origem comum (muitas vezes mítica), mas dialeticamente (in)-dependentes, em contradição, negação ou negociação dos quadros organizacionais estatais e territoriais tradicionais. A teoria da globalização, através de seus principais formuladores, não deixou de chamar a atenção sobre essa correlação dialética existente entre o processo de globalização e a tendência generalizada de des / reterritorialização e de reenraizamentos locais, particulares e transnacionais.

A mesma teoria é, com certeza, bastante prolixa (e geralmente benevolente) quanto ao "iminente" esvaziamento das funções reguladoras do Estado-Nação, sua "extinção" anunciada, a aparição de novas formas de sociabilidade, o ressurgimento de antigos e arcaicos tribalismos e a formação de novas bacias de subjetividades emancipadas do controle espacial e da gestão territorial. A figura do Estado-Nação, nesse tipo de literatura produzida pelos globais think tanks e agências especialistas comprometidas com o Capital Internacional, não passa de uma anomalia histórica desde o início fadada ao fracasso e a diluição.

Se faz aqui, todavia, imperativo um posicionamento filosófica organizacional claro e sem ambigüidade: o comunitarismo aberto, progressista e progressivo, tanto na teoria como na prática, não se opõe ao espírito republicano favorável à manutenção e consolidação do Estado-Nação. Pelo contrário, ele acredita e confia no papel vital do Estado enquanto garante dos direitos de todas as minorias e todas as comunidades de todas as naturezas. Partindo do princípio que só um Estado forte é capaz de assegurar a neutralidade das leis e a supremacia dos princípios republicanos e preservar os direitos de todos, os partidários deste tipo de comunitarismo elegem o quadro estatal (de destino) como a base primeira e o referencial imediato de sua ação social e política.

O pluri-pertencimento identitário, nessa perspectiva, não significa a superação ou a negação dos deveres cívicos locais do território de acolhimento, mas sim a conciliação sincera, honesta, generosa e igualitária entre os diferentes quadros simbólicos de identificação. Não se trata de colocar uma estrutura imaginária discursiva - organizacional contra ou acima da outra, mas sim optar por uma visão complementar que, em vez de separar, junta e, em vez de empobrecer, enriquece. 
Assumindo a sua narrativa polifônica e a sua identidade compósita, as comunidades abertas buscam se realizar na diversidade, sem medo da diferença ou da alteridade. Considerando o Humano como Uno e Universal (de um universalismo ele próprio aberto e mutável), o comunitarismo aberto acredita na convivência harmoniosa e na possibilidade concreta de construir territórios comuns regidos pelo princípio da complementaridade que acresce as totalidades e multiplica as sinergias.

Na filosofia construtivista desta forma plural de se agregar, a insistência nos direitos comunitários e a sua prática convicta não devem ser percebidas como contrárias aos ideais republicanos e democráticos, mas sim são ritornelos conceituais existenciais que se sobpõem ao exercício da cidadania plena e incondicional. Dito de outro modo, o (multi) pertencimento comunitário é, em si, uma maneira efetiva e concreta de negociar a cidadania total no espaço democrático republicano (a seus níveis cultural, social, político, etc...) e ensaiar de facto seus diversos e possíveis sentidos e desdobramentos.

Já a fábula do fim do Estado reflete, na verdade, o desejo apenas disfarçado das comunidades fechadas, sectárias e exclusivistas que recusam a idéia de compartilhar o espaço político igualitariamente e privilegiam os laços transnacionais (étnicos, confessionais, culturais, lingüísticos, sanguíneos, etc...) em detrimento da convivência civil e democrática. O território de destino, para eles, não passa de uma etapa estratégica de solidificação de seus objetivos inconfessos, uma ilha espaciotemporal no seu percurso histórico, um parêntese existencial ou uma provação escatológica no seu delírio hermético.

É nesse quadro civilizacional confuso e tumultuoso que se vê, hoje, florescer em todo o mundo o desejo de elaboração de novas instâncias de produção da subjetividade e de enunciação das singularidades. Como se pode constatar na maior parte do planeta, globalismo versus localismos, particularismos ou transnacionalismos são as duas faces de um mesmo fenômeno; onde o processo vem provocando reações abruptas e muitas vezes violentas por parte das culturas e das identidades singulares ou minoritárias. Reações que vão dos mais cruéis e sangrentos enfrentamentos até as mais diversas revoluções moleculares e estratégias micropolíticas de reterritorialização, reformulação e re-apropriação de territórios existenciais e espaços públicos ou comunitários. 
De fato, ao mesmo tempo que assistimos à interconexão das diferentes partes do planeta no já real "sistema-mundo" e à globalização de certos aspectos das culturas locais, se faz cada vez mais insistente a inconformidade com as fórmulas identitárias clássicas, buscando e propondo novos modos e novas modalidades de reenraizamento na diferença de seus respectivos "aqui e agora". Assim, neste contexto de crises e rupturas, as identidades étnicas e culturais se tornam o verdadeiro motor da História, abrindo o caminho para a nova configuração política mundial de ordem, não mais ideológica no sentido tradicional, mas sim geocultural.

A perspectiva geocultural, como vem sendo amargamente experimentada, não deixa espaço crítico para as realidades sociais, políticas ou econômicas, reduzindo o mundo e a totalidades dos mecanismos que o sustentam à idéia errônea dos princípios culturais irredutíveis e necessariamente belicosos. As conseqüências desta dramática essencialização da cultura (que não passa de uma nova roupagem para o antigo racismo biológico) se vêm agindo, por toda parte, como um discurso auto-referente total e uma profecia auto-realizada perfeita, capazes de subsidiar todos os extremismos e fanatismos de performantes programas de bestialização ideológica e (re) ação odiosa.

É à luz desta triste realidade histórica que a organização comunitária e o pluri-pertencimento devem ser apreendidos, analisados e instrumentalizados. Já que, como foi exposto, o comunitarismo pode ser tanto uma filosofia progressista e progressiva como uma prática retrógrada, reacionária e regressiva. Em todos os casos, o estudo de seus aparelhos, sistemas e interfaces podem se revelar valiosos instrumentos epistemológicos que ajudem a entender e prevenir os possíveis conflitos evidentes ou latentes que a sociedade contemporânea incuba.

\section{Estrutura Discursiva e Lutas Simbólicas}

Ao desvelar a natureza política, ideológica e estratégica da CIC, fica manifesta a necessidade urgente de elaborar uma estrutura epistêmica capaz de medir os movimentos e oscilações nos quadros simbólicos de identificação dos grupos étnicos e confessionais, tais como são ecoados pelos discursos de sua mídia comunitária ou através do posicionamento de seus membros na esfera midiática pública. Uma radiografia geral desses quadros e um detalhamento sistemático de 
seus contornos em função das especificidades de cada grupo e/ou à luz de eventos extraordinários internos ou externos, se impõem com vigor e vivacidade para o campo de nossos estudos e as trilhas de nossa pesquisas.

A interpelação parece lógica e pertinente; já que a CIC, sob a forma de mídia comunitária ou através da presença comunitária na mídia geral tem, de fato, esse mérito de oferecer um discurso reflexivo, organizado, aberto e público sobre o próprio grupo, sobre os Outros e sobre o mundo. Não é preciso lembrar que toda identidade é construída a partir de narrativas sobre si mesmo e sobre o Outro, mas, no caso específico dos grupos minoritários (étnicos e confessionais), é na base deste exercício que eles elaboram as suas estratégias de legitimação e formação de consenso, tanto entre o seu público interno como junto à sociedade.

É verdade que existem outros canais e outras modalidades de comunicação comunitária que contribuem na formação da complexa paisagem ideológica do grupo. Como são múltiplas as práticas e instâncias sociais e culturais que subtendem as estruturas imaginárias, subjetivas e simbólicas de toda coletividade humana, independentemente de seus marcos identitários. Contudo, a vantagem dos processos comunicacionais institucionalizados reside na sua representatividade política estabelecida e reconhecida tanto pela sociedade geral como pelos próprios membros do grupo.

Alem de ser essencial para a produção, reprodução e circulação de sentido dentro e fora do grupo, o discurso elaborado pelos meios formais de comunicação comunitária constitui em si uma construção ideológica reflexiva (em autoria e autoridade) que objetiva provocar voluntariamente um impacto na cognição social de seus receptores internos e externos. Desempenhando assim, um papel intencional crucial na validação, expressão e legitimação de seu universo social, cultural e político, aos próprios olhos dos membros do grupo e aos olhos do mundo.

Não é por acaso que os grupos culturais espalhados pelo mundo, geralmente são dotados de uma eficiente mídia comunitária que ajuda a assegurar a sua coesão social, cultural e política aos níveis local, regional, nacional e global. Há, neste dado estatístico, um indício efetivo do quanto é vital para esses grupos poder se manifestar sobre a realidade social e política na qual eles se inserem para se posicionarem com 
relação à sociedade e oferecer a seus membros um quadro coerente de ação e argumentação.

Existe, decerto, uma correlação estreita entre as formas organizacionais de uma comunidade e as instâncias de enunciação de seu projeto socio-histórico, na medida que, ao elaborar as suas práticas discursivas, ela procura desenvolver estratégias que atuem como dispositivos simbólicos na disputa pela imposição de sentido (ainda que plural e polifônico) tanto junto a seus próprios membros como junto à sociedade em geral. O que elege a CIC como superfície ideal para a observação e a análise das múltiplas dinâmicas sociais, culturais e políticas que se dão no encontro entre as diferentes comunidades componentes da sociedade e o encontro de cada uma delas com a sociedade geral.

Por outro lado, a mesma CIC, enquanto processo comunicacional, serve de plataforma de reivindicação dos marcos identitários indispensáveis para a perenidade do ethos do grupo e de cenário de negociação dos possíveis territórios existenciais e subjetivos necessários para sua integração plena na sociedade acolhedora. As modelagens discursivas são, com efeito, um dos principais recursos utilizados pelas comunidades minoritárias no seu esforço de se pensar enquanto projeto social, político e filosófico e, ao mesmo tempo, simular as possibilidades de negociação deste projeto com o conjunto da sociedade.

De fato, se, como sabemos, os diferentes grupos e classes estão sempre envolvidos numa "bourdivina" luta simbólica no afã de negociar e impor a definição do mundo mais conforme aos seus interesses sociais, culturais e políticos, os discursos desenvolvidos por eles constituem o melhor barômetro para compreender e discernir os objetivos e as regras desta luta; já que toda organização social é estruturada, primeiramente e antes de nada, no plano discursivo.

Portanto, a importância dos discursos politicamente fundamentados e socialmente coerentes não se limita à sua capacidade de representação do real, mas sim se sustenta por sua eficácia em produzir sentido e estabelecer o consenso necessário para a sobrevivência do grupo enquanto tal e o sucesso político, social e identitário de seus membros tanto dentro do grupo como no seu relacionamento diário com os diversos segmentos da sociedade na sua totalidade. 
Enfim, a centralidade da CIC para a apreensão da questão intercultural, no contexto contemporâneo, se justifica mais ainda pelo fato de o locus de luta pelo poder, de negociação dos papéis sociais e posicionamentos políticos tem migrado do espaço público físico material tradicional para o espaço midiático virtual. Tornando, assim, os processos comunicacionais institucionais um dos principais pilares da democracia republicana e um recurso imprescindível para o acesso igualitário de todos aos meios de disputa deste poder; seja ele real, material ou simbólico.

O que implica que a CIC (comunicação comunitária própria e presença efetiva como agente e sujeito na mídia geral) é um direito e requisito fundamentais para a negociação da cidadania pelos diferentes grupos culturais no contexto da “Sociedade de Informação". Já que não se pode mais negar que a visibilidade midiática, em suas várias e variadas formas, goza, hoje mais de que nunca, de um real poder político e é vestida de uma autoridade social e moral plenamente representativa.

O outro lado desta implicação, todavia, é que essa nova esfera de visibilidade-representatividade (locus por excelência de negociação e de luta pelo poder) não pode ficar oculta aos olhos da República (no seu sentido original de Res Publica) e ao campo de observação e análise da Sociedade Civil. Na medida que o mesmo ideal democrático republicano que deve assegurar a todos as mesmas condições de acesso aos instrumentos de expressão, argumentação e ação, também exige total e absoluta transparência de toda atividade social a caráter público ou cujos efeitos diretos ou indiretos concernem o conjunto da coletividade.

Por todos esses motivos, se pode concluir que a CIC, tanto meios, processo e conteúdo como objeto de estudo e análise constitui uma esfera social, política, discursiva, epistemológica e cognitiva que merece uma atenção especial por parte dos estudos de comunicação e toda a área de ciências humanas e sociais. 


\section{Bibliografía:}

ALSINA, M. R. (2004). “Cuestionamientos, Características y Miradas de la Interculturalidad”. In Sphera Publica. No. 4. Murcia - Espanha: Universidad Católica San Antonio.

DEMORGON, J (1989). L'Exploration Interculturelle. Paris: Armand Colin.

DEMORGON, J (1996). Complexité des Cultures et de l'Interculturel. Paris: Anthropos.

ELHAJJI. M. (2004). "Comunicação, Cultura e Novas Formas de Conflituosidade”. In Sphera Publica. No. 4. Murcia - Espanha: Universidad Católica San Antonio.

LADMIRAL, J.-R. et Lipianski, E.M (1996). La Communication Interculturelle. Paris: Armand Colin.

ROJAS, C. V. (2004) “Genelogía Crítica de la Comunicacíon Intercultural”. In Sphera Publica. No. 4. Murcia - Espanha: Universidad Católica San Antonio. 